\title{
The impact and prevalence of SARS-CoV-2 in patients with head and neck cancer and acute upper airway infection in a tertiary otorhinolaryngology referral center in Denmark
}

\author{
Peter Anders Andersen ${ }^{1}$ (1) - Kasper Møller Boje Rasmussen ${ }^{1} \cdot$ Hani Ibrahim Channir ${ }^{1}$. Christian von Buchwald ${ }^{1,3}$. \\ Per Cayé-Thomasen ${ }^{1,3} \cdot$ Mads Klokker $^{1,3} \cdot$ Jenny Dahl Knudsen ${ }^{2} \cdot$ Nikolai Søren Kirkby $^{2} \cdot$ Kasper Aanaes $^{1,3}$. \\ Ramon Gordon Jensen ${ }^{1,3}$
}

Received: 28 September 2020 / Accepted: 20 November 2020 / Published online: 3 January 2021

(c) Springer-Verlag GmbH Germany, part of Springer Nature 2021

\begin{abstract}
Purpose To determine the prevalence of SARS-CoV-2 at a Danish tertiary referral otorhinolaryngology clinic during the first wave of the COVID-19 pandemic among patients with suspected acute upper airway infection (UAI) and patients operated for head and neck cancer (HNC), respectively. To monitor changes in the number of patient encounters for acute UAI and the number of referrals for the workup of HNC. Trial registration: NCT-04356560 (Clinicaltrials.gov).

Methods Prospective enrolled case series of all patients with suspected acute UAI $(n=88)$ and of patients undergoing surgery for HNC ( $n=96)$, respectively, from March 23rd to May 5th, 2020, at a public tertiary referral otorhinolaryngology clinic in Denmark. SARS-CoV-2 was diagnosed with nasopharyngeal and oropharyngeal swabbing. Patients with suspected acute UAI had symptoms and definitive diagnoses registered in a database. Trends in the number of referrals and patient encounters were retrieved from an electronic patient journal system and analyzed retrospectively.

Results Eighty-eight patients with acute UAI were enrolled including 55 men and 34 women, median age of 31 years (range: 10 months to 82 years). One patient (1.1\%) tested positive. Among 96 patients operated for HNC, zero tested positive. The number of referrals for HNC workup, and patient encounters for peritonsillar abscesses, decreased markedly in the first 3 weeks.

Conclusion The prevalence of SARS-CoV-2 during the first 6 weeks of the first wave was minimal among patients with acute UAI and zero among patients operated for HNC. The decrease in referrals for the workup of HNC may increase time to treatment initiation and patient morbidity.
\end{abstract}

Keywords Severe acute respiratory syndrome coronavirus $2 \cdot$ Head and neck neoplasms · Otolaryngology · COVID-19 . Respiratory tract infections · Tertiary care centers

Supplementary Information The online version contains supplementary material available at https://doi.org/10.1007/s0040 5-020-06514-6.

Peter Anders Andersen

andersenpetera@gmail.com

1 Department of Otorhinolaryngology, Head and Neck Surgery and Audiology, Rigshospitalet, Copenhagen University Hospital, Blegdamsvej 9, 2100 Copenhagen, Denmark

2 Department of Clinical Microbiology, Rigshospitalet, Copenhagen University Hospital, Copenhagen, Denmark

3 Faculty of Health and Medical Sciences, University of Copenhagen, Copenhagen, Denmark

\section{Introduction}

The Coronavirus Disease 2019 (COVID-19) pandemic has changed the clinical setting for ear, nose, and throat (ENT) departments, due to the occupational risk of infection and subsequent mortality from COVID-19 [1]. This has been attributed to a high viral load of the severe acute respiratory syndrome coronavirus 2 (SARS-CoV-2) in the nasal mucosa and the uncertainty of whether patients presenting with acute ENT illness also harbor SARS-CoV-2 co-infection $[1,2]$

Case reports have shown the occurrence of SARS-CoV-2 among known infectious upper airway complications such as peritonsillar abscess, acute bacterial otitis media, and rhinosinusitis [3-5]. Furthermore, it is known that acute bacterial 
middle ear infections are associated with viruses in $80 \%$ of cases, including coronaviruses [6,7].

Adding to the uncertainty of whether an ENT patient may be co-infected with SARS-CoV-2 is the wide range of presenting symptoms among COVID-19 patients, ranging from asymptomatic to respiratory distress, with the majority of patients exhibiting mild illness [8-10]. Among hospitalized cases, one study showed that $67 \%$ of cases initially presented as an upper respiratory tract infection, and a systematic review showed that the prevalence of sore throat and nasal congestion were $12 \%$ and $4 \%$, respectively $[11,12]$.

Contributing to the altered clinical setting are the structural and behavioral changes in society that have been imposed to contain infection. In Denmark, lockdown measures were implemented at an early stage during the first wave, from March 13 to 18th, 2020 [13]. Hospitals rescaled their services to only treat urgent disease and cancer [14]. General practitioners (GP) continued to act as gatekeepers for referral to hospitals and increased their use of telemedicine $[15,16]$. The impact of the increased use of telemedicine on referral patterns for patients with acute upper airway infection and patients with head and neck cancer were unknown.

Therefore, to mitigate the risk of nosocomial infection at our department, the primary purpose of our study was to prospectively investigate the occurrence of SARS-CoV-2 among ENT patients with suspected acute upper airway infection and patients surgically treated for head and neck cancer.

Secondarily, we investigated the impact of the increased use of telemedicine and social distancing measures on our otorhinolaryngology service. We retrospectively analyzed trends in the number of referrals for the workup of head and neck cancer, and trends in the number of patient encounters for the two most common acute upper airway infectious conditions.

\section{Methods}

\section{Study setting}

As a tertiary referral center, the department receives urgent referrals from municipalities in the capital region of Denmark covering a population of approximately 1,035,000 citizens [17]. Furthermore, the department covers up to 2,700,000 citizens in case of diagnosing and treating head and neck cancer. The majority of referrals are from GPs and out-patient ENT clinics in the primary care sector [18, 19]. The public healthcare system in Denmark is free for all citizens and the majority of patients are treated by general practitioners that refer patients to other services when necessary [20].

\section{Study design}

A prospectively enrolled case series of two groups was conducted during a 6-week time period, from March 23rd to May 5th, 2020.

Group I consisted of patients that had a suspected acute upper airway infection. The aim was to investigate the prevalence of SARS-CoV-2 and register the frequency of symptoms and diagnoses among these patients. Patients referred to the ENT out-patient clinic for the diagnosis and treatment of a suspected acute upper airway infectious condition, or patients that had developed acute upper airway infectious symptoms during their stay in the surgical ward were included.

Patients in group I were tested for SARS-CoV-2 as part of their clinical workup upon their first consultation and every subsequent consultation until last clinical follow-up. Information regarding the date of onset, symptoms upon presentation at the clinic, SARS-CoV-2 status, and the patient's final diagnosis were registered in a database. As shown in Table 2, the presence of a subset of symptoms was of interest for our study, and, therefore, routinely registered in the database.

Group II consisted of all patients that underwent surgery for head and neck cancer. Included patients were tested 2-3 days before surgical treatment, and their SARS$\mathrm{CoV}-2$ status was registered. Symptoms and other characteristics were not collected for this part of the study.

No patients that met the inclusion criteria were excluded from testing in both groups.

To investigate the impact of the pandemic on our department, we performed a retrospective review of our center's electronic medical journal system data. The reviewed data were from January to May 2020, thus capturing the period before and after social distancing measures were implemented during the first wave. For comparison, we queried the same data from the corresponding period in the previous year, January-May 2019.

The number of weekly referrals for the workup of head and neck cancer was used as a variable to show differences in the activity of the head and neck cancer service. To visualize changes in the level of activity for services related to acute upper airway infection, we analyzed the number of monthly patient encounters for acute tonsillitis and peritonsillar abscess, as these were the two most frequent conditions in our case series.

\section{SARS-CoV-2 testing}

All tests were performed by ENT physicians. Testing was performed on nasopharyngeal and oropharyngeal 
mucosa by swab sampling. Oropharyngeal testing was performed by sampling at least one tonsil and the posterior oropharyngeal wall [21]. Nasopharyngeal testing was performed unilaterally by inserting the swab via the nasal cavity, at least $2 / 3$ into the nasopharynx, and simultaneously rotating on retraction. Both swabs were transported in the same tube and medium (Copan UTM or similar) and analyzed at the Department of Clinical Microbiology, Rigshospitalet. SARS-CoV-2-RNA were detected either by the Cobas[®] SARS-CoV-2 real-time RT-PCR test on the Cobas 6800 system (Roche, Switzerland) or using the RealStar ${ }^{\circledR}$ SARS-CoV-2 RT-PCR Kit (Altona, Germany). In brief: The nucleic acids in the patient sample were extracted together with an internal RNA control, using magnetic silica particles, and transferred to a specific RTPCR, targeting two separate gene segments.

\section{Distribution of diagnoses from patients with suspected acute upper airway infection}

The frequencies of different diagnoses among all registered diagnoses in our database of patients with suspected acute upper airway infection are calculated and listed in Table 1 . The frequency of acute tonsillitis, peritonsillar abscess, acute sinusitis, and acute mastoiditis are listed separately, and the remaining diagnoses are clustered into categories due to their low frequency during the study period. A full overview of ICD-10 diagnoses and their frequency can be found in the Supplemental Material, Table 3.

Table 1 Distribution of patient diagnoses that were tested for SARSCoV-2 co-infection, due to suspected acute upper airway infection, in the period of March 23rd-May 5th, 2020

\begin{tabular}{ll}
\hline Diagnosis & No. $(\%)$ \\
\hline Acute tonsillitis & $22(25.0)$ \\
Peritonsillar abscess Other phlegmone or abscess $^{1}$ & $21(23.9)$ \\
Non-infectious conditions $^{2}$ & $15(17.1)$ \\
Other infectious conditions $^{3}$ & $8(9.1)$ \\
Viral upper airway infection $^{4}$ & $9(10.2)$ \\
Acute sinusitis $_{\text {Acute mastoiditis }}$ & $6(6.8)$ \\
Total $(n)$ & $4(4.5)$ \\
\hline
\end{tabular}

Specification of categories. (1) Abscess of mouth, infection following a procedure, erysipelas, abscess of the nose, pulpitis, sialadenitis, and cutaneous abscess of the face or neck. (2) Nasal fracture, epistaxis, dyspnea, pain in throat, dizziness, angioneurotic edema, and perforation of esophagus. (3) Neutropenic fever, localized lymph node enlargement, candidal stomatitis, otitis externa, cough, and fever. (4) Infectious mononucleosis, acute pharyngitis, and acute upper respiratory infection

\section{Number of patient encounters and referrals}

Data for the number of referrals and patient encounters were obtained from an electronic patient file system: Epic Hyperspace, November 2019 version (Epic Systems Corporation, Verona, WI, USA).

\section{Ethics approval}

The study was approved in accordance to national guidelines by the National Committee on Health Research Ethics, journal-number H-20026456.

\section{Results}

\section{Prevalence of SARS-CoV-2 in patients with acute upper airway infection}

The study included 88 patients, 54 men and 34 women. The median age was 31 years, ranging from 10 months to 82 years. A total of 119 tests were performed, corresponding to 1.4 tests per patient. Only one patient $(1.1 \%)$ tested positive for SARS-CoV-2, and thus, 87 patients tested negative. The median duration of symptoms till referral was 4 days. 86 patients were initially tested upon referral at the out-patient clinic, one patient was tested after the development of acute upper airway infectious symptoms in the surgical ward, and one patient was readmitted to the surgical ward due to postoperative infection.

As shown in Table 1, the two most frequent UAI conditions were acute tonsillitis and peritonsillar abscess. Patients referred with non-infectious conditions and where SARS-CoV-2 infection was suspected later through the course of treatment consisted of $9 \%$ of all tested patients. The frequency of complications to viral infection, such as acute ethmoid sinusitis and acute mastoiditis, was 5\% and 3\% of tested patients, respectively. The SARS-CoV2-positive patient was diagnosed with acute pharyngitis. The patient was received for workup and treatment on April 14th, 4 weeks after initial lockdown measures were implemented.

Symptoms upon referral are listed in Table 2. We found sore throat $(59.1 \%)$ and fever $(39.8 \%)$ to be the two most frequent symptoms. Hyposmia was reported by five patients $(5.7 \%)$. Hyposmia was among the symptoms of the SARS-CoV-2-positive patient. The four other hyposmic patients tested negative, and were diagnosed with peritonsillar abscess, nasal fracture, postoperative infection, and acute ethmoidal sinusitis, respectively. 
Table 2 The distribution of symptoms in patients with suspected SARS-CoV-2 co-infection at our department, in the period March 23rd-May 5th, 2020 (cumulative data)

\begin{tabular}{lc}
\hline Symptom & No. $(\%)$ \\
\hline Sore throat & $52(59.1)$ \\
Fever & $35(39.8)$ \\
Trismus & $18(20.4)$ \\
Ear pain & $16(18.2)$ \\
Dry cough & $10(11.4)$ \\
Fatigue & $10(11.4)$ \\
Headache & $10(11.4)$ \\
Hyposmia & $5(5.7)$ \\
Arthralgia & $4(4.5)$ \\
Nasal congestion & $4(4.5)$ \\
Gastrointestinal symptoms & $4(4.5)$ \\
Periorbital swelling & $4(4.5)$ \\
Rhinorrhea & $3(3.4)$ \\
Eye symptoms & $3(3.4)$ \\
Aural protrusion & $3(3.4$ \\
Dysgeusia & $2(2.3)$ \\
Aural fullness & $1(1.1)$ \\
\hline
\end{tabular}

\section{Prevalence of SARS-CoV-2 among patients with head and neck cancer}

In the study period March 23rd-May 5th, 96 patients underwent surgery for head and neck cancer. Zero patients tested positive for SARS-CoV-2.

\section{Monthly trends in the number of consultations for acute tonsillitis and peritonsillar abscess}

Using aggregated data from the electronic patient file system, we found that the number of patient encounters for peritonsillar abscess and acute tonsillitis was lower in 2020 than 2019 during the study period. The monthly number of patient encounters diagnosed with peritonsillar abscess was markedly lower in April 2020 when compared with April 2019 (Fig. 1). We did not see the same pronounced decrease in patient encounters for acute tonsillitis (Fig. 2).
Fig. 1 Number of patient encounters with peritonsillar abscess

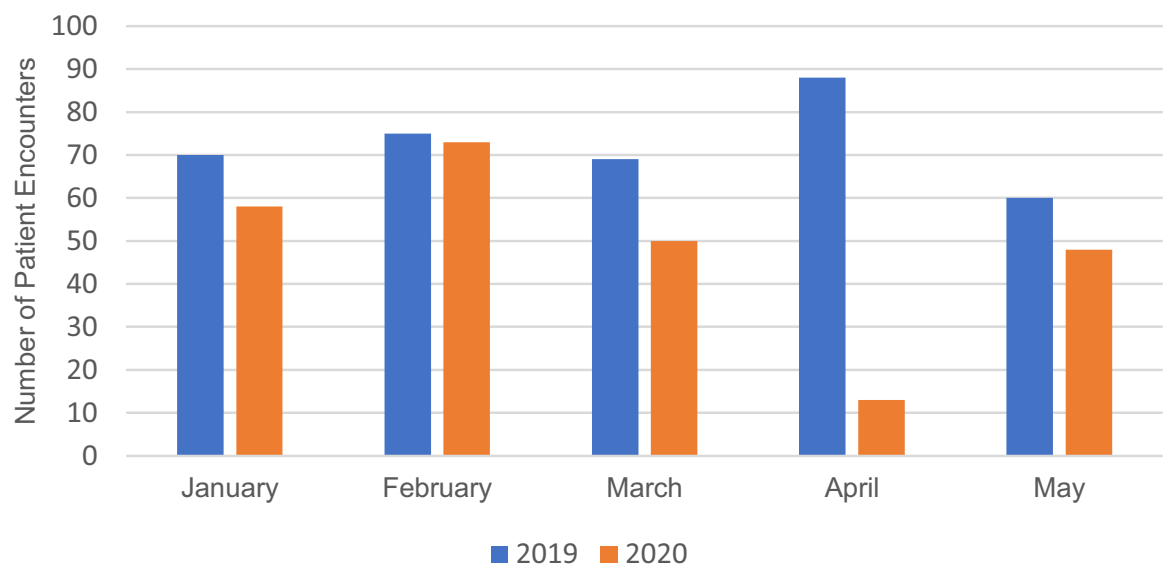

Fig. 2 Number of patient encounters with acute tonsillitis

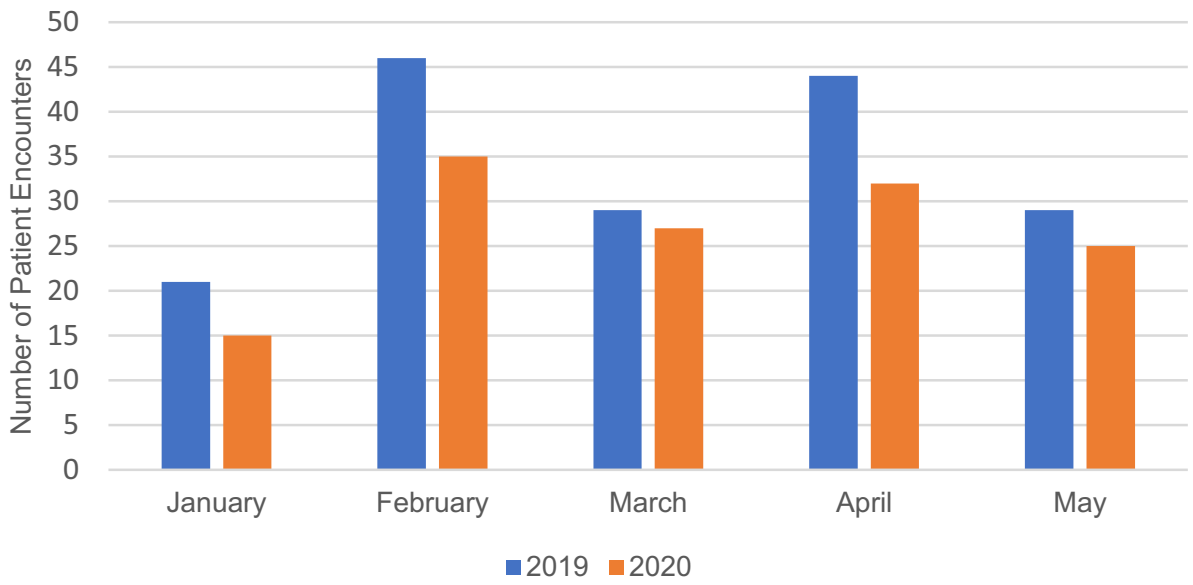




\section{Weekly trends in the number of referrals for the workup of head and neck cancer}

We found an overall reduced number of patients referred for the diagnosis and treatment of head and neck cancer in 2020. During the periods from January to May, we received 506 and 630 referrals for the years 2020 and 2019, respectively. The most pronounced drop in referrals was seen in April during calendar week nr. 15, which was 3 weeks after initial social distancing, and lockdown measures were implemented. It was then followed by an increase in referrals in calendar weeks nr. 16-18 (Fig. 3).

\section{Discussion}

Our approach differs from other reports that characterized patients which were already confirmed to have COVID-19. We aimed in our case series to investigate the occurrence of unidentified cases among ENT patients due to the overlap of common symptoms such as sore throat and nasal congestion [22].

As shown in the results of our case series, we found only one (1.1\%) SARS-CoV-2-positive patient among 88 ENT patients with acute upper airway infectious symptoms. We found zero SARS-CoV-2-positive cases among 96 head and neck cancer patients that underwent surgery. A similar prevalence has been found in the preliminary results from population-based representative seroprevalence studies that were released on May 20th, which estimated the prevalence of SARS-CoV-2 infection in the population of Denmark to be $1.1 \%(0.5-1.8)$ [23]. However, only $41.2 \%$ of the invited subjects participated in the seroprevalence studies. Swedish seroprevalence studies from samples obtained in Stockholm on May 3rd estimated a prevalence of 7.2\% [24]. It would be of interest to investigate if the higher seroprevalence in the Swedish population coincided with a similar prevalence among Swedish ENT patients. Finally, ENT patients without symptoms indicating upper airway infection were not tested, and the prevalence in this population remains unknown.

When our data are compared to other European reports of samples that consisted of COVID-19 cases, the data from our case series show a higher occurrence of other symptoms, evidently due to the high proportion patients diagnosed with peritonsillar abscess and acute tonsillitis. Among COVID-19 patients with mild-to-moderate disease, Lechien et al. reported frequencies of headache (70.3\%), hyposmia (70.2\%), nasal obstruction (67.8\%), cough $(63.2 \%)$, asthenia $(63.3 \%)$, myalgia $(62.5 \%)$, rhinorrhea $(60.1 \%)$ and gustatory dysfunction (54.2\%), and sore throat (52.9\%) [25]. Among our case series, the most common symptoms were sore throat (59.1\%), fever (39.8\%), trismus (20.4\%), ear pain $(18.2 \%)$, dry cough $(11.4 \%)$, fatigue (11.4\%), and headache (11.4\%).

In our retrospective query of patient encounters, we found a reduced number of patient encounters related to peritonsillar abscess during the first wave, which is similar to findings from two other reports [26, 27]. Seasonal changes could be a source of bias, but a Danish study from 2017 showed no significance for the seasonal variation in the incidence of peritonsillar abscesses [28]. The reduction in the number of patient encounters related to peritonsillar abscess, coinciding with a period of social distancing, suggests that viral infection could be a driver for the development of the condition.

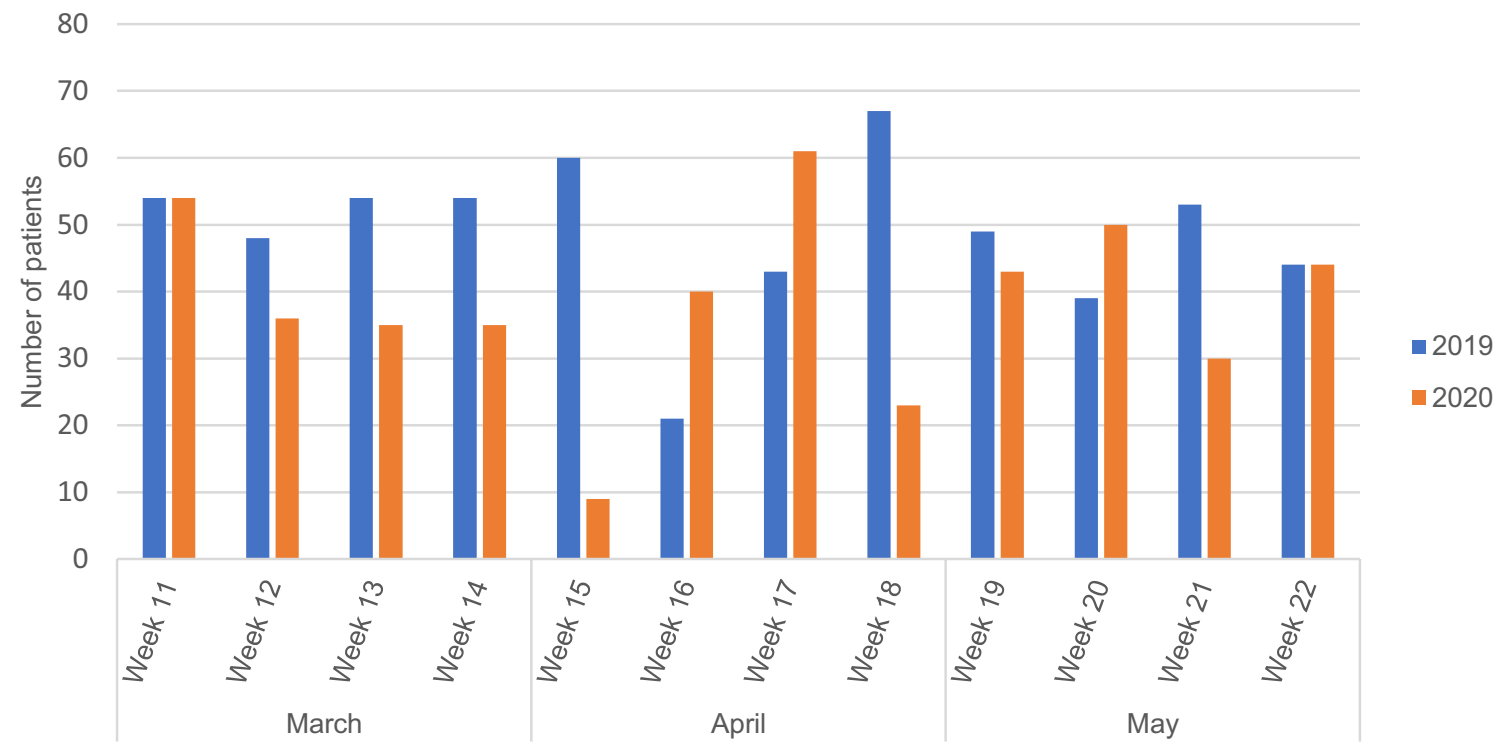

Fig. 3 Number of referrals per week for the diagnosis and treatment of head and neck cancer 
However, we did not observe the same trend in the number of patient encounters related to acute tonsillitis. This is in contrast to another study, which found a reduction in tonsillitis episodes during a 2-month period of social distancing in a pediatric population [29].

Our results support concern about the vulnerability of head and neck cancer patients during times of social distancing [30]. The total number of referrals for the workup of head and neck cancer is markedly lower in 2020 when compared to 2019. The noticeable reduction in referrals seen in April, during calendar week nr. 15, followed by a rebound in the following weeks, indicates a delay, which in the current setting could be a combination of both patient's and doctor's delay. Some patients may have disregarded their symptoms to avoid burdening the public health system, and others may have perceived the public health system as a high-risk area for SARS-CoV-2 infection and, therefore, avoided it. Finally, the assessment of unspecific symptoms may be impeded by telemedicine, leading to a doctor's delay. Whatever the cause, this may result in delayed diagnostic work-up, treatment, and a poorer prognosis [31].

\section{Limitations}

A selection bias in the findings of our case series is possible. Patients who were suspected for COVID-19 showing moderate-to-severe illness, were assessed by a GP and then in selected cases referred to centers specialized in the diagnosis and treatment of COVID-19 [16]. Therefore, the vast majority of COVID-19 patients with upper airway symptoms may not initially have been referred to our ENT department. Nonetheless, if a COVID-19 patient required treatment for a viral upper airway complication, we would have expected an increase in demand for this type of consult, which was not the case (unpublished data). It is also possible that upper airway symptoms were mild, and therefore did not prompt ENT consultation. Data from the primary sector out-patient ENT clinics were not included in this study due to difficult access to representative data. We assume that their uptake of patients did not increase dramatically, in part due to national shortages of personal protective equipment in the study period. Finally, some of the nasopharyngeal and oropharyngeal swab test results could have been false negative. However, a low SARS-CoV-2 prevalence among patients seems plausible, due to the similar low prevalence of infection among personnel in our department (unpublished data).

Our findings in the retrospective analysis of the number of patient encounters for acute tonsillitis could be due to a redirection of cases to our center due to the possible reduced activity of primary sector out-patient ENT clinics, thus creating a false impression of an unchanged number of patient encounters. Similarly, it is also likely that the restricted access to personal protective equipment and increased use of telemedicine by GPs may have impeded clinical assessment, thus lowering the threshold for referral to our center. Finally, a limitation to this type of data could be incorrect coding in the electronic patient file system. We expect this bias to have been relatively unchanged in 2019 and 2020.

The findings of this study can be compared to countries with similar public healthcare systems such as Norway, Sweden, Finland, and Iceland. The generalization of our results is restricted by differences in the national prevalence of SARS-CoV-2 and in the handling of the COVID-19 pandemic, particularly regarding the extent of social distancing measures and the structural organization of the response to the pandemic in the healthcare system.

\section{Conclusion}

We found one COVID-19 case among 88 patients with symptoms of acute upper airway infection during the first wave of the COVID-19 pandemic. The two most common acute upper airway infectious conditions were acute tonsillitis and peritonsillar abscess. We found a reduced overall number of patient encounters for both conditions in 2020 .

No head and neck cancer patients tested positive for SARS-CoV-2. Our data show a pronounced drop in the number of referrals for the workup of head and neck cancer occurring 3 weeks after social distancing measures were implemented, which may have resulted in increased time to treatment initiation and patient morbidity.

Author contributions Study design: RGJ, KA, and HIC. Drafting of the manuscript: PAA. Revision of the manuscript: all authors. Final approval: all authors. Final agreement: all authors.

Funding No funds, grants, or other support was received.

Data availability All the data are freely available by contacting the corresponding author.

\section{Compliance with ethical standards}

Conflict of interest The authors have no relevant financial or non-financial interests to disclose.

Ethical approval The study has been approved in accordance to national guidelines by the National Committee on Health Research Ethics, journal number H-20026456.

Informed consent Informed consent was obtained from all individual participants included in the study.

\section{References}

1. COVID-19 (2020). https://www.ceorlhns.org/covid-19. Accessed 9 Jun 2020 
2. Zou L, Ruan F, Huang M et al (2020) SARS-CoV-2 viral load in upper respiratory specimens of infected patients. N Engl J Med 382:1177-1179

3. Sideris AW, Ghosh N, Lam ME, Mackay SG (2020) Peritonsillar abscess and concomitant COVID-19 in a 21-year-old male. BMJ Case Rep 13:238104. https://doi.org/10.1136/bcr-2020-238104

4. Turbin RE, Wawrzusin PJ, Sakla NM et al (2020) Orbital cellulitis, sinusitis and intracranial abnormalities in two adolescents with COVID-19. Orbit. https://doi.org/10.1080/01676830.2020.17685 60

5. Fidan V (2020) New type of corona virus induced acute otitis media in adult. Am J Otolaryngol Head Neck Med Surg 19:102487. https://doi.org/10.1016/j.amjoto.2020.102487

6. Alper CM, Winther B, Mandel EM et al (2009) Rate of concurrent otitis media in upper respiratory tract infections with specific viruses. Arch Otolaryngol Head Neck Surg 135:17-21. https://doi. org/10.1001/archotol.135.1.17

7. Schilder AGM, Chonmaitree T, Cripps AW et al (2016) Otitis media. Nat Rev Dis Prim. https://doi.org/10.1038/nrdp.2016.63

8. Kronbichler A, Kresse D, Yoon S et al (2020) Asymptomatic patients as a source of COVID-19 infections: A systematic review and meta-analysis. Int J Infect Dis. https://doi.org/10.1016/j. ijid.2020.06.052

9. Day M (2020) Covid-19: four fifths of cases are asymptomatic, China figures indicate. BMJ 369:m1375. https://doi.org/10.1136/ bmj.m1375

10. Wu Z, McGoogan JM (2020) Characteristics of and important lessons from the Coronavirus Disease 2019 (COVID-19) outbreak in China: summary of a report of 72314 cases from the Chinese center for disease control and prevention. J Am Med Assoc 323:1239-1242

11. Young BE, Ong SWX, Kalimuddin S et al (2020) Epidemiologic features and clinical course of patients infected with SARSCoV-2 in Singapore. J Am Med Assoc 323:1488-1494. https:// doi.org/10.1001/jama.2020.3204

12. Lovato A, de Filippis C (2020) Clinical presentation of COVID19: a systematic review focusing on upper airway symptoms. Ear Nose Throat J. https://doi.org/10.1177/0145561320920762

13. Pressemøde i Spejlsalen om COVID-19-Regeringen.dk (2020). https://www.regeringen.dk/nyheder/2020/pressemoede-i-spej1 salen-om-covid-19/. Accessed 28 Jun 2020

14. Sundhedsstyrelsen (2020). https://www.sst.dk/da/Nyheder/2020/ Saadan-skal-sygehusene-prioritere-deres-arbejde-under-COVID -19. Accessed 28 Jun 2020

15. General public-Danish Health Authority (2020). https://www.sst. dk/en/English/Corona-eng/General_public. Accessed 22 Jun 2020

16. Sundhedsstyrelsen (2020). https://www.sst.dk/da/Udgivelser /2020/Retningslinjer-for-haandtering-af-COVID-19. Accessed $11 \mathrm{Jul} 2020$

17. Region Hovedstaden (2015) Hospitalsplan 2020. Hillerød. https:// www.regionh.dk/til-fagfolk/Sundhed/hospitaler/HOPP/Tidligerehospitalsplaner/Sider/Tidligere-hospitalsplaner.aspx

18. Sundhedsstyrelsen (2020). https://www.sst.dk/da/Udgivelser /2020/Pakkeforloeb-for-hoved-og-halskraeft. Accessed 28 Jun 2020
19. Til Fagfolk (2020). https://dahanca.dk/page1.html\#header1-u. Accessed 28 Jun 2020

20. Sundheds-og Ældreministeriet Healthcare in Denmark-sum.dk (2020). https://www.sum.dk/English/Healthcare-in-DenmarkAn-Overview.aspx. Accessed 22 Jun 2020

21. Sådan poder man for Covid-19 korrekt (2020). https://www.rigsh ospitalet.dk/presse-og-nyt/nyheder/nyheder/Sider/2020/marts/ saadan-poder-man-for-covid-19-korrekt.aspx. Accessed 9 Jun 2020

22. Özçelik Korkmaz M, Eğilmez OK, Özçelik MA, Güven M (2020) Otolaryngological manifestations of hospitalised patients with confirmed COVID-19 infection. Eur Arch Oto-Rhino-Laryngol 1:3. https://doi.org/10.1007/s00405-020-06396-8

23. De første foreløbige resultater af undersøgelsen for COVID-19 i befolkningen er nu klar (2020). https://www.ssi.dk/aktuelt/nyhed er/2020/de-forste-forelobige-resultater-af-undersogelsen-for-covid -19-i-befolkningen-er-nu-klar. Accessed 30 Jul 2020

24. Första resultaten från pågående undersökning av antikroppar för covid-19-virus Folkhälsomyndigheten (2020). https://www.folkh alsomyndigheten.se/nyheter-och-press/nyhetsarkiv/2020/maj/forst a-resultaten-fran-pagaende-undersokning-av-antikroppar-forcovid-19-virus/. Accessed 30 Jul 2020

25. Lechien JR, Chiesa-Estomba CM, Place S et al (2020) Clinical and epidemiological characteristics of 1,420 european patients with mild-to-moderate coronavirus disease 2019. J Intern Med. https ://doi.org/10.1111/joim.13089

26. Gelardi M, Iannuzzi L, Trecca EMC et al (2020) COVID-19: what happened to all of the otolaryngology emergencies? Eur Arch OtoRhino-Laryngol. https://doi.org/10.1007/s00405-020-06046-Z

27. Ralli M, Minni A, Candelori F et al (2020) Effects of COVID-19 Pandemic on Otolaryngology Surgery in Italy: The Experience of Our University Hospital. Otolaryngol Neck Surg. https://doi. org/10.1177/0194599820928970

28. Klug TE (2017) Peritonsillar abscess: clinical aspects of microbiology, risk factors, and the association with parapharyngeal abscess. Dan Med J 64:B5333

29. Heward E, Rocke J, Kumar N, Izzat S (2020) Recurrent tonsillitis and parental perceptions of tonsillectomy during the COVID-19 pandemic. Int J Pediatr Otorhinolaryngol 139:110463. https://doi. org/10.1016/j.ijporl.2020.110463

30. Adjei Boakye E, Jenkins W, Sharma A (2020) Disproportionate impact of COVID-19 pandemic on head and neck cancer survivors. Head Neck. https://doi.org/10.1002/hed.26170

31. Liao DZ, Schlecht NF, Rosenblatt G et al (2019) Association of delayed time to treatment initiation with overall survival and recurrence among patients with head and neck squamous cell carcinoma in an underserved urban population. JAMA Otolaryngol Head Neck Surg. https://doi.org/10.1001/jamaoto.2019.2414

Publisher's Note Springer Nature remains neutral with regard to jurisdictional claims in published maps and institutional affiliations. 